\title{
Fictional Persuasion and the Nature of Belief
}

\author{
Asbjørn Steglich-Petersen \\ Aarhus University \\ Forthcoming in: \\ Ema Sullivan-Bissett, Helen Bradley, and Paul Noordhof (eds.) Art and the Nature of \\ Belief. Oxford University Press.
}

\section{Introduction}

Psychological studies on fictional persuasion demonstrate that being engaged with fiction systematically affects our beliefs about the real world, in ways that seem insensitive to the truth. This threatens to undermine the widely accepted view that beliefs are essentially regulated in ways that tend to ensure their truth, and may tempt various non-doxastic interpretations of the belief-seeming attitudes we form as a result of engaging with fiction. In this paper, I evaluate this threat, and argue that it is benign. Even if the relevant attitudes are best seen as genuine beliefs, as I think they often are, their lack of appropriate sensitivity to the truth does not undermine the essential tie between belief and truth. To this end, I shall consider what I take to be the three most plausible models of the cognitive mechanisms underlying fictional persuasion, and argue that on none of these models does fictional persuasion undermine the essential truth-tie.

I will proceed as follows. In Section 2, I provide an introduction to the relevant psychological findings on fictional persuasion, and briefly motivate what I will assume for the sake of argument in the remaining part of the paper, namely that the relevant attitudes caused by engaging with fiction should be seen as genuine beliefs. In Section 3, I introduce a number of versions of the widely accepted idea that beliefs are essentially regulated for truth, and explain why fictional persuasion may be seen to threaten this idea. To fix matters for the following discussion, I will in the end focus on the version of the essential truth regulation, according to which beliefs are essentially regulated by cognitive mechanisms that have as their biological proper function to ensure truth. In Section 4, I consider what I take to be the three most plausible explanatory models of the cognitive mechanisms underlying fictional persuasion, namely the model developed by Dan Gilbert and colleagues, a more parsimonious model recently suggested appealing to the availability heuristic, and a model that I adapt from theories of narrative as a distinct evolved cognitive process. I argue that all of these models make the psychological findings on fictional persuasion compatible with beliefs being essentially regulated for truth. Finally, in Section 5, I consider and reject an objection from fictional persuasion to my own preferred theory of the aim of belief, raised by Ema Sullivan-Bissett and Lisa Bortolotti in their contribution to this volume.

\section{Fictional Persuasion}

Psychological studies over the past 25 years have demonstrated that being engaged with fiction and narrative often affects our real world beliefs. This section will provide a brief overview of these findings. ${ }^{1}$

In an early series of studies (Gerrig and Prentice 1991; Prentice et al. 1997; Prentice and Gerrig 1999; Wheeler et al. 1999), subjects read fictional stories containing various general statements, asserted as part of the fiction, but with real world application,

${ }^{1}$ I draw in this section on the excellent summary of the psychological findings in Friend (2014). 
that were either true (e.g. 'Mental illness is not contagious') or false (e.g. 'Mental illness is contagious'). The subjects were subsequently asked to answer a general knowledge questionnaire, and were found to agree with statements that were consistent with the fiction and disagree with statements that were inconsistent with the fiction, to a higher degree than subjects who had read an unrelated story. Other studies (Marsh et al. 2003; March and Fazio 2006; Butler et al. 2012) focused on the effect of statements contained in stories in a more peripheral way, and again, subjects were found to answer in accordance with the story in subsequent knowledge tests to a statistically significant higher degree than control groups. The same was found when subjects were asked questions the answer of which had to be derived from the story, rather than being explicitly contained in them.

Strikingly, a study reported by Deborah A. Prentice and Richard J. Gerrig (1999) showed that subjects were more likely to be affected in these ways if they thought they were reading fiction, rather than a factual account: subjects in two groups read the same text, but in the one group, the text was labeled as fiction, while in the other the text was labeled as journalism. The persuasive effects were found to be higher in the group reading the text labeled as fiction. A similar result is reported by Jeffrey J. Strange (2002). It is also interesting to note that factors, which reduce persuasion in rhetorical contexts, such as higher intelligence and 'need for cognition', did not reduce fictional persuasion (Wheeler et al. 1999).

In a particularly influential study, Melanie C. Green and Timothy C. Brock (2000) demonstrate a correlation between the degree of narrative effects on real world beliefs, and the degree to which subjects report being deeply absorbed into the narrative - a 'distinct mental process, and integrative melding of attention, imagery, and feelings' (p.701) that Green and Brock call 'transportation'. Level of transportation was measured according to subjects' reporting of experiencing things such as ease of picturing events in the story, lack of attention of surroundings while reading, ability to picture themselves in the narrative, mental involvement, disability to put narrative out of their minds after reading it, emotional effects, interest in alternative endings, and more (p.704).

In the study, Green and Brock had subjects read a short story, 'Murder in the Mall', and found that those reporting a high degree of transportation were subsequently more likely to assent to story-consistent statements, such as 'The likelihood of death by stabbing in a mall is quite high', 'Psychiatric patients who live in an institution should not be allowed out in the community during the day', 'The world is violent and unjust', etc. These findings were independent of whether the subjects thought they were reading fiction or non-fiction.

The nature of the statements assented to in the study by Green and Brock might tempt some to interpret the attitude change as a matter of change in non-doxastic states rather than beliefs. Especially the last two of the statements mentioned above invite this interpretation, since they are of a normative nature and therefore, according to some, not truth-apt, and thus unsuitable as contents of beliefs. ${ }^{2}$ But when seen together with the results of the previous studies, which focused on statements that clearly were truth-apt, it seems plausible to take Green and Brocks findings as corroborating the earlier ones.

Another possible motivation for preferring a non-doxastic interpretation is the relative instability of the attitudes affected by fiction. Marsh et al. (2003) tested the effects after a delay, and the change in attitudes was found to be less pronounced, suggesting that the attitudes in question were of a less stable kind, such as temporary acceptance. However, when attitudes were tested both immediately after reading the

\footnotetext{
2 This would be the preferred interpretation of non-cognitivists about normative statements. For an overview, see Mark Schroeder (2008).
} 
fiction, and then again after a delay, the attitudes were retained to a higher degree, which suggests that the instability was a matter of lack of memory, rather than the nature of the attitudes (Friend 2014).

While there may well be more to be said in favor of the non-doxastic interpretations of the studies on fictional persuasion, I shall assume for the sake of argument that the studies do demonstrate effects on genuine beliefs. My interest in this paper is to assess the tension between the findings on fictional persuasion and the idea that beliefs are essentially regulated for truth, on the assumption that the findings do indeed concern genuine beliefs. And while I grant that this assumption is not beyond doubt, it is plausible enough, I think, to warrant the project of this paper. ${ }^{3}$

Before moving on, I should set aside some more reliable ways in which reading fiction can lead to real world beliefs. It seems clear that a reader of fiction could adopt various conscious strategies for extracting reliable information from the fiction. Anna Ichino and Gregory Currie (this volume) point out, for example, that when it comes to certain background facts and scenarios for the stories played out in works of fiction, authors typically prefer to stick to the truth unless there is some special reason not to, and we typically think more highly of works of fiction that are truthful in this way. Although there are a number of pitfalls that one should steer clear of (cf. Friend 2014), this means that, for at least some of these background facts, we can rely on authors to form reliable beliefs on the assumption of their truthfulness. As pointed out by Dustin Stokes (2006), we can also rely on works of fiction as a source of modal knowledge about possibilities. Imagination is often thought to aid knowledge of possibility, since the ability to imagine the truth of some proposition can be taken as evidence that the proposition could be true. ${ }^{4}$ Since works of fiction help us imagine propositions and scenarios that we would not otherwise have imagined, or perhaps been able to imagine, they help us come to reliable beliefs about possibilities. Furthermore, as argued by James Young (this volume), the psychological phenomenon of 'experience-taking' described by Kaufman and Libby (2012), where readers of fiction spontaneously simulate the thoughts and emotions of fictional characters, can in some cases modify readers' beliefs in epistemically reliable ways by enabling them to view the world from a new perspective. Finally, there is knowledge of the 'deeper' truths of morality and human psychology, of which the humanistic tradition in aesthetics credits art as a source (Gaut 2006). I mention these examples only to set them aside, however. My interest in this paper solely concerns the sort of beliefs and belief-forming processes uncovered by the psychological studies on fictional persuasion - beliefs that, at least initially, seem hostile to the idea that beliefs are essentially regulated for truth. I shall now turn to outline that idea.

\section{The Essential Truth-Tie and Misbelief}

\subsection{The Essential Truth-Tie}

A prevailing assumption among belief theorists is that belief bears an essential relation to the truth. Normatively speaking, there is something successful or correct about a belief being true, and something defective or incorrect about false beliefs. Causally speaking, if someone's attitude to some propositional is sufficiently unresponsive to the truth, or systematically fails to make the subject of the attitude behave in ways that would be

\footnotetext{
${ }^{3}$ See Sullivan-Bissett and Bortolotti (this volume), and Buckwalter and Tullman (this volume) for more comprehensive defenses of the doxastic interpretation.

${ }^{4}$ This idea is sometimes identified as the 'conceivability thesis' in the epistemology of modality. For an overview, see Vaidya (2007).
} 
rational in light of the truth of its content, it becomes difficult to think that attitude as a genuine belief. These considerations seem basic to the nature of belief (Williams 1973).

These general and vague ideas have been interpreted in a number of different ways, which has given rise to a number of competing theories of belief. We can approach the idea by first considering some weaker and inessential relationships between belief and the truth, that fail to demarcate belief from other attitudes (Velleman 2000). Observe first that believing some proposition $p$ involves believing $p$ to be true. This clearly does not set belief apart from other propositional attitudes - even conative propositional attitudes, such as desires, involve an attitude to the truth of a proposition. Desiring $p$, is desiring $p$ to be true. We get closer to belief when we observe that believing $p$ involves regarding $p$ as true. Desires do not share this characteristic. But other cognitive attitudes do. Accepting, supposing, imagining, etc., arguably all involve regarding $p$ as true. If the essential truth-tie is to demarcate belief, it must therefore consist in some stronger relation than this.

The perhaps most parsimonious account of the essential truth-tie is purely functional/causal. ${ }^{5}$ A simple version of this account (helping ourselves now to an account of propositional content) identifies beliefs with, roughly, whatever propositional attitude that plays the functional role of being caused in ways that tend to ensure the truth of the propositional content, and of causing actions that tend to satisfy the believer's desires if the content is true. It is widely accepted that causal relationships such as these do indeed capture an important aspect of belief. But many think that the functionalist account is nonetheless inadequate as it stands. One familiar problem is that the account fails to capture the normative flavor of the relation to truth. It is not simply an unexplained essential fact about belief that they are causally regulated for truth, and that they tend to cause actions that are successful when the beliefs are true. Rather, beliefs stand in these causal relationships because they thereby fulfill their normative or rational role (Zangwill 1998; Shah 2003). Indeed, it is only by a virtue of a prior understanding of this normative role that functionalists are able to identify the functional role of belief - not by careful empirical observation of causal patterns involving beliefs, but by reflection on the conditions under which beliefs would be rational or make other attitudes or actions rational (Davidson 1980).

In order to account for issues such as these, many have been attracted to an account of the essential truth-tie that it purely normative. ${ }^{6}$ According to one such interpretation, beliefs are essentially such that they, in some sense, ought to be or are correct only if true. This sets belief apart from both conative and other cognitive attitudes of the kinds mentioned above. Although there is a sense in which it is good for one's desires to become true, it is only good if it is the world that comes into conformity with one's desire, rather than the other way around. Beliefs, by contrast, are correct when they conform to the world - a difference in what is known as 'direction of fit' (Anscombe 1957). And when it comes to accepting, supposing, imagining, and the like, there doesn't seem to be any good and general sense at all in which we prefer them to be true - for example, we often suppose some proposition to be true only in order to prove it false.

But there are serious problems with the purely normative proposal. If the difference between beliefs and other sorts of attitudes is, at bottom, a normative one, beliefs have normative essences - they are constitutively normative. But in what sense of 'ought' is it really the case that all beliefs, no matter the content or occasion, ought to be true? And how does an essentially normative account of belief fit within a naturalistic

\footnotetext{
${ }^{5}$ For a representative sample, see Putnam (1967), Lewis (1970), and Fodor (1981).

${ }^{6}$ For a representative sample, see Adler (2006), Boghossian (2008), Engel (2004), Fassio (2011), Shah and Velleman (2005), Wedgwood (2007), and Whiting (2010). For a recent overview, see McHugh and Whiting (2014).
} 
account of psychology? It is also all but clear that the normative account succeeds on it's own terms in solving the problem faced by the functionalist account. Just as the causal roles played by belief call for explanation, the normative roles of belief call for explanation too - we should be unsatisfied with an account that bottoms out in certain constitutive norms, the force of which themselves cry out for explanation. ${ }^{7}$

An account seeking to ground the normative tie between belief and the truth in more fundamental features of belief, and at the same time explain its causal role, is the teleological account of belief, according to which believing $p$ involves having as an aim or intention to believe $p$ truly. ${ }^{8}$ Such an aim or intention gives rise to normative assessments, albeit of an instrumental nature, in the same way that having various practical aims could make some actions more suitable or rational relative to the aim, than others. This account has the advantage over the purely normative account of not involving any inherently normative aspect to belief, which would be problematic from a naturalistic perspective, while explaining the nature and relevance of evaluating beliefs in terms of truth. ${ }^{9}$

It is a contested issue, however, how to best understand the nature of the aim involved with believing, on the teleological account. Although beliefs may sometimes be under the regulation of a literal aim or intention of a believer, the vast majority of beliefs clearly are not. David Velleman (2000) handled this difficulty by proposing that the aim of believing the truth can be realized not only at the personal level by literal intentions, but also at the sub-personal level by cognitive systems that have as their biologically proper function to ensure the truth of the beliefs that they regulate. This also remains my own preferred theory, and I have defended it in previous work from various objections (see footnote 9). Other theorists have proposed proper function accounts of belief's relation to truth independently of the role such functions might play in realizing the 'aim' postulated by teleologists. ${ }^{10}$

In the bulk of this paper, I will focus on whether beliefs arising from fictional persuasion present a problem for the explanation of belief's essential relation to truth in terms of biologically proper functions, and argue that they do not. I focus on this explanation in part because of its relative wide acceptance, and therefore interest; but since my own preferred account also involves appeal to mechanisms having as their biologically proper function to ensure the truth of beliefs, my defense of this idea also provides indirect support for my own account. However, in their contribution to this volume, Ema Sullivan-Bissett and Lisa Bortolotti argue that fictional persuasion presents a special problem of my aim based account. In the final section, I argue that it doesn't.

\subsection{Proper function and misbelief}

It is no simple matter to state what it means for some organ, system, behavior, etc., to have some feature as its proper function. On Millikan's (1984) influential account, the proper function of some $x$ has to do with its etiology. Following Allan Hazlett's (2013) useful statement of Millikan's account, we may say that to $\phi$ is the biological proper function of $x$, where $x$ is a part or feature of an organism o, whenever (i) the ancestors of

\footnotetext{
${ }^{7}$ For criticisms of the normative account of belief and other propositional attitudes, see Steglich-Petersen (2006a; 2008a; 2008b; 2011a; 2013a).

${ }^{8}$ For an influential statement of this account, see Velleman (2000). For further development and defense, see Steglich-Petersen (2006b; 2009; 2010; 2011b; 2013b; 2013c).

${ }^{9}$ That is not to say, of course, that the account is entirely unproblematic from a naturalistic perspective; intentionality remains naturalistically challenging.

${ }^{10}$ For a representative sample, see Millkan (1984), Papineau (1993), and Neander (1995), and SullivanBissett and Bortolotti (this volume).
} 
o had $\mathrm{x}$, or some 'ancestor' of $\mathrm{x}$, and the fact that their $\mathrm{x} \phi$-ed provided them a reproductive advantage, (ii) there are genes for having $\mathrm{x}$, and for having $\mathrm{x}$ that $\phi$, and (iii) the truth of (i) and (ii) explains why o has $\mathrm{x}$.

This allows us to give a more precise characterization of truth being the proper function of belief, keeping in mind that this function is a matter of the cognitive systems regulating beliefs having as their proper function to ensure true belief. Following Hazlett (2013) again, this comes to the following: (i) the ancestors of humans had beliefregulating cognitive systems, or 'ancestors' of such systems, and the fact that the cognitive systems ensured true beliefs provided them a reproductive advantage; (ii) there are genes for having cognitive systems, and for having cognitive systems that ensure true beliefs; and (iii) the truth of (i) and (ii) explains why humans have the belief-regulating cognitive systems that they have.

Given this characterization of the essential truth-tie, we can turn to formulating our main question anew. The question now becomes: do the psychological findings on fictional persuasion undermine the view that the proper function of belief is to be true? It is easy to see why one might suppose that the findings do undermine this view. It is of course compatible with $\phi$-ing being the proper function of $\mathrm{x}$, that $\mathrm{x}$ sometimes fails to $\phi$. The existence of heart failure does not undermine that the proper function of hearts is to circulate blood. Proper functions are compatible even with quite pervasive failure, as in the case of sperm cells failing at staggering rates in reaching their target (Millikan 1984: 34). But whenever the 'failure' becomes sufficiently systematic, it raises the question of whether it is a failure at all in the proper function sense. What is a systematic 'failure' when seen from the perspective of one function may turn out to instead be a surprising adaptation in response to an unconsidered problem, revealing the proper function to be something entirely different. To properly undermine the proper function, however, the 'failure' must be shown to itself represent a heritable feature or behavior, that provided our ancestors with a reproductive advantage separate from that provided under the originally hypothesized proper function, such that it explains the current existence of that feature or behavior. The question, now, is whether the findings on fictional persuasion undermine truth as the proper function of belief in this way.

The findings on fictional persuasion certainly do represent a pattern of belief formation that systematically fails to be truth-sensitive. Might this pattern reveal a surprising adaptive function of belief and belief-regulating systems that is insensitive or to the truth? Again, not necessarily: there are other systematic failures of cognitive systems to yield true beliefs that clearly are compatible with truth being their proper function. A stick that is half submerged in water appears bent, and this appearance will lead us to believe that it is bent unless we consciously correct for the refraction of light as it passes from the water to the air. This is a clear and systematic weakness of our perceptual belief forming system, when seen from the point of view of ensuring true beliefs. But no one would be tempted to say that this weakness reveals that the system has some alternative adaptive function, apart from ensuring true beliefs. There is no reproductive advantage to be had from having straight sticks appear to one as bent. We would rather explain this weakness as a matter of evolution economizing with our cognitive means. The advantage afforded by a perceptual system that corrects for refracting light simply doesn't outweigh the cognitive cost of developing and running such a system. But this does nothing to undermine the view that what the perceptual system is selected to do, is to ensure true beliefs. To make a parallel, strong prescription lenses curve the light along the edges of the lens, causing a distorted impression when wearing them. But this is an accidental and regrettable feature of the lenses that we would rather be without or minimize, if it were possible or less expensive, and could thus hardly be said to be the function of the lenses. There is no easy argument, then, from 
some systematic failure of a cognitive system in causing true beliefs, to truth not being the proper function of that system. To undermine truth as the proper function, we would have to show that the non-truth sensitive nature of the relevant cognitive system is heritable and provides a reproductive advantage other than the mere advantage of being 'cheaper' than a system that tracks the truth.

To judge whether the findings on fictional persuasion undermine truth as the proper function, we must first understand the cognitive mechanisms at play in fictional persuasion. We must then try to determine whether the unreliability of those mechanisms is a matter of a truth-independent adaptation, in the above sense. Determining the psychological mechanisms in particular is no easy task, and not one that I can hope to carry out here with any confidence. Instead, I will consider three plausible candidates for the mechanism, some of which have been proposed in the literature, and ask for each of those whether they, if they indeed are responsible for fictional persuasion, undermine truth as the proper function of belief.

\section{Three Models of Fictional Persuasion and The Essential Truth-Tie}

\subsection{The Gilbert Model}

The prevailing explanatory model in the psychological literature of the findings on fictional persuasion invokes a general model of belief formation suggested by Dan Gilbert and colleagues (1993). Gilbert et al. contrast the prevailing 'Cartesian' model of belief formation, with their preferred model inspired by Spinoza. On the Cartesian model, comprehension and belief formation are two distinct processes. When we hear or read some sentence, it is first processed for comprehension, thus yielding a propositional content, and only following this do we take up or reject the content for belief. Gilbert et al. contrast this view with the 'Spinozan' theory, according to which comprehension and belief formation are parts of one and the same cognitive process. When we hear or read a sentence, the content of the sentence is initially accepted as part of the comprehension process. It then requires subsequent processing to evaluate and possibly delete the acceptance, something that requires cognitive effort, and if the acceptance isn't subjected to this active evaluation, it will linger and become a belief. The chief prediction of this theory is that when some event or factor stands in the way of someone 'undoing' the initial acceptance, he will continue to believe the content, even if it would be judged false upon consideration.

In the original study motivating this model, subjects were thus exposed to false information about a criminal defendant or a college student to see whether various distractions would have an effect on subsequent belief. Some subjects were exposed to this information while under cognitive load, others under time pressure. They were then asked to make judgments related to the defendant or student, and it was found that both load and time pressure caused subjects to believe the false information and to use it in making consequential decisions about the target. Gilbert et al. took these findings to confirm their model, on the interpretation that both manipulations prevented subjects from "unbelieving" the false information they automatically believed during comprehension. Although there are clearly other possible interpretations of the findings that do not support Gilbert et al.'s model, I shall not pursue those here.

It is easy see how Gilbert's model might be recruited to explain the findings on fictional persuasion. The model does not predict, of course, that all of the beliefs formed as part of the comprehension process will persist. It only predicts that the beliefs linger when various circumstances, such as cognitive load or time pressure, prevent us from weeding out beliefs as we go along. But engagement with a fictional story, and more 
specifically fictional 'transportation', can easily be seen as one such distracting circumstance. As our attention becomes absorbed by the narrative, and our critical vigilance lowered as a result of being aware that one is engaging with fiction rather than statements of fact, we become less prone to weeding out the acceptances that are formed in the process of comprehending the sentences making up the fictional story, and some of them thus end up as beliefs.

There are a number of reasons to doubt this explanation (see Ichino and Currie (this volume) for a brief discussion). For one, it is unclear in what sense one could automatically believe everything one reads and hears, since it is unclear what content one would believe. As Sperber et al. (2010) point out, it always takes pragmatic processing to work out what content utterances or written words signify, which means that at least part of the comprehension process must take place prior to the adoption of acceptance or belief. Gilbert's model also makes it difficult to explain why we are more prone to adopt belief in some parts of fictional contents than others. In particular, we are more likely to take up belief in fictional contents that form part of the fictional background, rather than in contents that are part of the main narrative. But why that should be so is unclear on Gilberts model. However, I shall not attempt to evaluate the explanation based on Gilbert's model here. The relevant question presently is whether fictional persuasion undermines truth as the proper function of belief, on the assumption that the Gilbert model correctly identifies the cognitive mechanisms responsible for fictional persuasion.

Why would evolution have favored a one-process rather than a two-process approach for comprehension and belief-formation? Why would evolution have favored initially believing everything one sees or hears, and only subsequently weeding out faulty beliefs, rather than letting all possible contents for beliefs pass through a gatekeeping system before we take up belief in them? One obvious explanation is cognitive economy. Critically evaluating contents for belief is a costly process. The potential benefit to be gained from this process is an increased probability of ending up with a true belief. But if a sufficiently high proportion of the contents one sees or hears are truthful already, there may be little to be gained from critically evaluating all of the contents, compared to the cost. For example, if 95 percent of what one sees or hears is truthful as it is, critically evaluating all contents is a high price for whatever modest increase in proportion of true belief one could gain as a result. On the one-process strategy, the subsequent evaluation could then select which beliefs to evaluate, based, for example, on the stakes involved with those particular beliefs, so as to ensure a high payoff on the cognitive effort. If this explanation of the one-process approach is right, and the one-process approach is what underlies fictional persuasion, beliefs from fiction no more undermine truth as the proper function of belief, than optical illusions do. They are the result of a cost conscious cognitive system that nevertheless has as its function to yield true beliefs.

Another obvious explanation of why evolution might have favored the oneprocess approach is speed. It is often beneficial to be able to act quickly on new information. But if all information must be evaluated for truth before it can be acted on, we are more likely to act too late to avoid whatever danger or attain whatever benefit indicated by the information. Add to this that acting on false information in cases where speed is of the essence will tend to be less costly - one can jump to avoid a snake-shaped branch many times before the cost of this outweighs the cost of being bitten by a snake reacted to too slowly. This means that there may be asymmetrical costs to sometimes acting on false information compared to acting too late on the information one has. This is a cost structure familiar from the literature on error management, studying situations with asymmetrical costs to adopting false positives and negatives. ${ }^{11}$ For example, it has

\footnotetext{
${ }^{11}$ See e.g. Stich (1990), Haselton and Buss (2000), and Haselton (2007).
} 
been suggested that men overestimate sexual interest in women because of asymmetrical costs to believing there to be interest when there is none (low cost), and believing there not be interest when there is (high opportunity cost). But it is also a familiar point from this literature that adapting to such cost structures in one's beliefs does nothing to undermine that our cognitive systems has as their function to ensure truth. Less fallible systems would all else being equal have been more adaptive, but their high cost would not outweigh the benefits (Hazlett 2013). Nevertheless, for all their fallibility, these systems have the biological function of producing true belief.

In sum, fictional persuasion does not seem to undermine truth as the proper function of belief, on the assumption that the Gilbert model correctly identifies the cognitive mechanisms responsible for fictional persuasion.

\subsection{The Availability Heuristic Model}

The second candidate mechanism for explaining the findings on fictional persuasion involves what is known as the 'availability' heuristic, described in Amos Tverski and Daniel Kahneman's classic study (1973). An explanation appealing to this is briefly suggested by Ichino and Currie (this volume). The availability heuristic is a hard to suppress mental shortcut that relies on ease of cognitive retrieval when making judgments about frequencies of classes or the probability of events. This can lead to biases in such judgments, insofar as recent examples or experiences are easier to retrieve than more distant ones.

Again, it is fairly obvious how the availability heuristic might be recruited to explain the findings on fictional persuasion. Engaging with fiction makes available examples of events, classes, associations, etc., and will thus make those examples salient and easy to retrieve for subsequent judgments of frequency and probability. As Ichino and Currie point out, Tverski and Kahneman in fact rely on the heuristic to explain a phenomenon very similar to that found in the later studies on fictional persuasion, namely that subjects rated nuclear war as more likely after having seen a movie depicting it, even though they were aware that the movie was fictional. If this phenomenon is indeed to be explained by the availability heuristic, it shows that this heuristic is blind to the distinction between real and fictional sources of information, thus lending support to the idea that the heuristic is what is responsible for the more general findings on fictional persuasion.

There are also reasons to be skeptical about this explanation, however. Why, for example, should the degree of transportation matter to fictional persuasion, if the heuristic is simply based on certain examples or associations being easily available for retrieval? At least, some supplementary explanation would be needed to account for the role of transportation, appealing perhaps to the effect that transportation has on memory. It is also doubtful that the availability heuristic is able to explain the variety of beliefs affected by fictional persuasion. The heuristic is most relevant in forming judgments of frequency and probability, and less likely to affect particular judgments, at least as the heuristic is usually and originally understood. To explain these latter kinds of judgments, we would thus have to suppose a more extended version of the heuristic, or introduce other mechanisms as supplements. However, as above, I shall not attempt to evaluate the explanation based on the availability heuristic here. The relevant question is whether fictional persuasion undermines truth as the proper function of belief, on the assumption that this explanation correctly identifies the cognitive mechanisms responsible for fictional persuasion.

It should be fairly obvious, however, that the availability heuristic does not threaten truth as the proper function of belief, from which it follows that fictional persuasion 
presents no such threat either, if it can be explained by the availability heuristic. As Tverski and Kahneman themselves in effect pointed out, any cognitive bias caused by the availability heuristic is a side-effect of what is normally a reliable strategy for arriving at reasonable estimates of frequency and probability. The heuristic is based on the essentially sound rule that 'instances of large classes are recalled better and faster than instances of less frequent classes, that likely occurrences are easier to imagine than unlikely ones, and that associative connections are strengthened when two events frequently co-occur' (1973: 208). This means that a person with some reliability can rely on ease of retrieval and mental association when making frequency and probability estimates. The potential bias caused by the strategy stems from the fact that ease of retrieval and mental association is also affected by less relevant (although not altogether irrelevant) factors, such as how recently one has experienced the relevant event or association between events. This means that when we rely on ease of retrieval, we run the risk of relying on the less relevant factor of recent experience rather than the more relevant factor of frequent experience. The reason we have evolved to rely on this imperfect strategy is, of course, that the cost of inaccuracy and bias in the judgments caused by the heuristic is outweighed by the benefits of speed and cognitive frugality. But this does not mean that there is something adaptive about the inaccuracy in itself, or that the inaccurate judgments possess some other truth-independent property, apart from being fast and frugal, that have promoted their evolutionary selection. So on the assumption that fictional persuasion is explained by the availability heuristic, it does not undermine truth as the proper function of belief.

\subsection{Fictional Persuasion as an Evolved Cognitive Process}

Whereas the previous two candidate explanations of fictional persuasion appealed to general features and mechanisms of human cognition, the last candidate explanation that I want to consider is tailored more specifically to explain cognitive processing of fiction and narrative.

Michelle S. Sugiyama (2001) summarizes research pointing to a number of features of our ability for narrative processing that supports regarding it as a relatively specialized evolutionary adaptation. For one thing, narrative is a universal cross-cultural phenomenon, existing in some form in all human societies, whether literal or not, in a comparable state of elaboration regardless of their state of technological advancement. The capacity to process and understand narrative is also universal across individuals within cultures, reliably developing without formal instruction around the age of $2^{1 / 2}$ or 3 years, with the ability to distinguish narrative and non-narrative uses of language developing even earlier (e.g. Sutton-Smith 1986). This is not what we should expect if narrative were a cultural invention. ${ }^{12}$ Furthermore, there is a striking thematic resemblance in the content of narratives across cultures, with certain universal topics and themes to do with cosmology, topography, animal behavior, plant characteristics, life and death, sex, marriage, deception and violence (e.g. Aarne 1961). Finally, but not least, narrative is a highly complex cognitive process, relying on the integration of a host of more specialized cognitive operations, including theory of mind, causal reasoning, spatial reasoning, and language. All of this indicates that narrative meets the standard requirements of specialized adaptive design - 'it is species typical, reliably developing, and exhibits a degree of complexity that is unlikely to have arisen by chance' (Sugiyama 2001: 222; cf. Williams 1966).

\footnotetext{
12 This does not mean that there couldn't be more specific cultural norms or institutions governing engagement with works of fiction, as suggested by e.g. Peter Lamarque (this volume) or Eva-Maria Konrad (this volume); it only means that narrative in general is not a cultural invention.
} 
This on its own is does not suffice to explain the findings on fictional persuasion. But the contours of an explanation begin to reveal themselves when we consider what specific challenges narrative might have evolved as an adaptation for. The first key to unraveling this is the context in which narrative developed. Reviewing a number of sources, Sugiyama places the development of narrative well before the emergence of agriculture, and therefore in a context where people depended on foraging for subsistence (2001: 223). This means that the selection pressures leading to the development of narrative were those faced by foragers. One of the main challenges to which narrative provided a solution in this context, argues Sugiyama, was the high cost involved in first-hand information acquisition for foraging purposes. Acquiring information first hand was costly and often dangerous, requiring substantial investments of time and energy, frequently without paying off by leading to sources of food. This means that foragers were critically dependent on cooperating in information gathering, and on developing effective means for transferring and storing information gathered by others. Although there may be other adaptive functions of narrative as well, such as social indoctrination and manipulation, Sugiyama argues that the primary adaptive function of narrative was to solve this problem.

Why would narrative be especially apt for this purpose? A number of features can be listed that points to narrative as an effective solution to a number of constraints on information acquisition (Sugiyama 2001: 228): narrative processing requires no physical exertion; narrative compresses time; narrative is a representation of experience from the point of view of a narrator; narrative provides an effective vehicle for information storage; narratives are highly memorable (Sperber (1985) points out that we easily recall stories that are comparable in informational complexity to 20 -digit numbers); and narrative appears well designed for comprehensive simulation of human habitat. To these features we may add that narrative is often highly goal oriented, following recognizable patterns of problem descriptions and solutions that can easily be remembered, and that narrative often causes emotional responses that can serve as amplifiers of experience and anchors for memory.

Although Sugiyama does not discuss the findings on fictional persuasion, or the role of transportation in causing beliefs, it is easy to see how they would fit with the above picture. In general, if the original adaptive function of narrative was to transfer information, it should come as no surprise that we are disposed to take up beliefs when processing narrative. More specifically, the various scale items used by Green and Brock to measure degree of transportation (ease of picturing events, lack of attention of surroundings, ability to picture oneself in narrative, mental involvement, emotional effects, interest in alternative endings, etc.) are all factors that we would consider highly effective in aiding transfer of information, if that is indeed the intention in a given act of communication. Just consider trying to give someone a set of complex instructions on how to solve a problem or reach a certain goal, in a way that will allow the listener to carry out these instructions by relying on the memory of what you say alone. Surely, we would expect this to be more successful if our instructions were put in a way that disposed the listener to picture what you describe, focus attention on your description, picture himself in your description, become emotionally invested, form counterfactual thoughts about various aspects of your description, etc.

As above, I will not at present attempt a full development and evaluation of the explanation of fictional persuasion in terms of narrative as an adapted response to the problem of information acquisition. Needless to say, the proposal raises a number of 
questions that I cannot consider here. ${ }^{13}$ The relevant issue for our purposes is whether fictional persuasion undermines truth as the proper function of belief, on the assumption that this explanation correctly identifies the cognitive mechanisms responsible for fictional persuasion, and we already have enough material to venture a cautious answer to that question - namely that it doesn't. In fact, if narrative processing were an adaptation for aiding information acquisition, the findings on fictional persuasion seem to support truth as the proper function of belief, rather than undermine it. This is compatible with the fact that fictional persuasion now, given our currently dominant uses of fiction, namely as entertainment, is an adversary factor in the efforts of our cognitive systems to ensure true beliefs. But all this means is that narrative processing has been adopted for a use that it didn't (primarily) evolve to serve, namely entertainment. We can compare this claim to similar claims in the literature concerning other apparently unreliable cognitive mechanisms. Daniel G. Goldstein and Gerd Gigerenzer (2002) argue, for example, that various cognitive heuristics that seem unreliable under certain test-conditions, and in conditions often encountered in modern life, are in fact reliable in the right environments, and that these might be the environments in which the heuristics evolved. The heuristics thus fail to show that beliefs are regulated by mechanisms not functioning to yield true beliefs. In the same vein, if unreliable fictional persuasion is a byproduct of a reliable and effective mechanism for information transfer, the fact that it now (mostly) results in unreliable beliefs does little to show that beliefs are regulated by non-truth functioning mechanisms.

\section{Fictional Persuasion and Teleology}

I have argued that beliefs from fiction do not undermine the idea that truth is the proper function of belief. As mentioned earlier, I also take this as support for my own preferred account of the aim of belief, according to which this aim can be realized both at the personal level by literal intentions, and at the sub-personal level by cognitive systems that have as their biologically proper function to ensure the truth of the beliefs that they regulate. However, in their contribution to this volume, Ema Sullivan-Bissett and Lisa Bortolotti argue that fictional persuasion represents a special problem of the aim based account. In this final section, I argue that it doesn't.

Sullivan-Bissett and Bortolotti's objection is a strengthened version of Nishi Shah's 'teleologist's dilemma'. According to Shah, any plausible theory of belief must explain what he calls 'doxastic transparency', namely that 'the deliberative question whether to believe that $p$ inevitably gives way to the factual question whether $p$, since the answer to the latter question will determine the answer to the former' (Shah 2006: 481; see also Shah 2003). Shah claims that his own normative theory of belief can explain transparency as a manifestation of believers' commitment to the norm that believing $p$ is correct if and only if $\mathrm{p}$ is true. Doxastic deliberation is framed by the concept of belief, and according to Shah, anyone competent with this concept must accept and reason in accordance with the truth-norm, thus resulting in transparency.

The teleologist, however, faces an intractable dilemma, according to Shah (2003). On the one hand, the teleologist must recognize that the concept of belief encompasses not only attitudes that are strictly regulated for truth, but also non-deliberative attitudes that are more imperfect in their truth-regulation. But if that is the case, it becomes unclear why being framed by the concept of belief should make doxastic deliberation exhibit transparency, in the strong way described by Shah. Why should the sensitivity to

\footnotetext{
${ }^{13}$ To mention one pertinent question, raised by an anonymous reviewer, how does the proposal account for the fact that we only believe a small and select proportion of propositions in fiction?
} 
truth in doxastic deliberation not be of the weaker kind, exhibited by non-deliberative belief formation? On the other hand, if the teleologist increases the level of truth regulation required for attitudes to count as beliefs, so as to account for transparency, the position will exclude many plausible instances of belief. The teleologist thus seems to face a dilemma.

My original response to this dilemma in my (2006a) built on the observation (which Shah acknowledges) that transparency of course doesn't entail that doxastic deliberation will always be settled in ways that are in fact sensitive to the truth, since the deliberator might be mistaken or biased, or otherwise confused in determining the truth. Transparency merely shows that believers always settle doxastic deliberation by settling to their own satisfaction whether the target proposition is true, however feeble their ability in doing so might be, which is perfectly compatible with de facto weak and imperfect truthregulation. So the framing by the concept of belief should only explain why doxastic deliberators attempt to let their deliberation be decided by determining the truth of the relevant proposition. Once we realize this, the air of a dilemma vanishes. There is no tension between the obvious fact that one can count as believing $p$ while failing to believe $p$ truly, or even failing in believing $p$ in a way that is particularly sensitive to the truth, and the idea that we in doxastic deliberation aim strictly at forming a true belief. The level of de facto truth-regulation required for an attitude to count as a belief can thus be quite low, even if transparency is driven by a strict concern for the truth from the believers' own perspective.

Sullivan-Bissett and Bortolotti object, however, that beliefs from fiction represent a class of beliefs that is so extremely insensitive to the truth, that it becomes implausible to think that there is a standard of truth-regulation common to all beliefs, that will at once allow beliefs from fiction as genuine beliefs, and explain doxastic transparency. Sullivan-Bissett and Bortolotti accept that the de facto level truth-regulation present in cases of transparency is lower than it appears to be from the deliberator's own perspective, but they still think that it is too high to be accounted for by the very low standard of regulation needed to include beliefs from fiction as beliefs.

In response to this objection, I should say first of all that I longer think that the teleologist is saddled with explaining transparency as described by Shah. As I argue in my (2013a), in cases where the question whether to believe that $p$ is transparent to whether $p$ is true, the former question is most plausibly interpreted as a question about truth expressed in terms of belief, in which case transparency shouldn't be explained in terms of the concept of belief at all. If that is the case, there is no 'teleologist's dilemma', and no strengthened version of it either. However, for the sake of argument, I will also consider Sullivan-Bissett and Bortolotti's objection on the assumption that transparency as described by Shah is a genuine phenomenon. Even granting this, however, I think that the following three considerations make it clear that their objection fails.

The first consideration, which is also relevant to the main discussion of this paper, is that although beliefs from fiction are formed in ways that seem systematically insensitive to the truth, nothing in the studies on fictional persuasion shows that these beliefs continue to be systematically insensitive to the truth after their formation. They do not show, for example, that beliefs from fiction are likely to subsequently persist in light of clear evidence of their falsity, or that they would be more resistant to argument than beliefs formed in more standard ways. Clearly, both of these aspects of truth regulation affect whether an attitude should count as a belief, and it is hard to see why truthinsensitive attitude formation couldn't be counterbalanced by subsequent truth-sensitive regulation, when determining whether the attitude counts as a belief. Sullivan-Bissett and Bortolotti would have to motivate this idea if their objection is to succeed. 
Secondly, Sullivan-Bissett and Bortolotti appear to overestimate the level of de facto truth regulation that must be present in cases of transparency. I think that it is clear that this level can be very low indeed. Just think of a person who is so confused or biased in his reasoning, that none of the consideration that he takes as relevant to whether $p$ is true are in fact even remotely relevant (perhaps he regards patterns on a piece of toasted bread as decisive evidence of the existence of God). The de facto level of sensitivity to the truth in such cases of belief formation is extremely low; yet, the doxastic reasoning of such a person could easily exhibit transparency, since he may well settle on whether to believe that $p$ by determining, to his own satisfaction, whether $p$ is true.

Thirdly, on the teleological account, it isn't the de facto level of truth-regulation present in all beliefs that explain transparency. To put it somewhat simply, transparency is explained by a fact about what agents try to do in doxastic deliberation (namely, coming to a true belief), not by how well believers in fact succeed in this. So the minimal level of truth-regulation present in all beliefs does not play this explanatory role at all. It is hard to say anything precise about what the minimal required level is, which is also apparent from the main discussion of this paper. But the discrepancy between beliefs formed through transparent deliberation, and beliefs from fiction, does not raise any principled obstacle to there being such a common minimal level.

\section{Conclusion}

I have argued that the psychological findings on fictional persuasion do not undermine the idea that truth is the proper function of belief, even though they represent an example of beliefs being systematically insensitive to the truth. None of the most plausible candidates for cognitive mechanisms underlying fictional persuasion can plausibly be seen as selected by evolution for their tendency to cause false or unreliable beliefs, even if they, as in the case of fictional persuasion, often do. As argued in the end, the findings on fictional persuasion also do not undermine the truth-aim teleological account of belief.

\section{References}

Aarne, A. (1961). The Types of the Folktale: A Classification and Bibliography. Helsinki: Academia Scientiarum Fennica.

Adler, Jonathan (2006). Belief's Own Ethics. MIT Press.

Anscombe, G.E.M. (1957). Intention. Oxford: Blackwell.

Boghossian, Paul A. (2008). Content and Justification: Philosophical Papers. Oxford University Press.

Butler, Andrew C.; Nancy A. Dennis; Elizabeth J. Marsh (2012). Inferring Facts from Fiction: Reading Correct and Incorrect Information Affects Memory for Related Information. Memory 20: 487-98.

Buckwater, Wesley \& Katherine Tullmann (XXXX). The genuine attitude view of fictional belief.

Davidson, Donald (1980). Mental Events. In Essays on Actions and Events. Oxford University Press, 207-225.

Engel, Pascal (2004). Truth and the Aim of Belief. In D. Gillies (ed.), Laws and Models in Science, London: King's College Press, 77-97.

Fassio, Davide (2011). Belief, Correctness and normativity. Logique Et Analyse 54 (216): 471.

Fodor, Jerry A. (1981). The mind-body problem. Scientific American 244:114-25.

Friend, Stacie (2014). Believing in Stories. In Greg Currie, Matthew Kieran, Aaron 
Meskin \& Jon Robson (eds.), Aesthetics and the Sciences of Mind. Oxford University Press. 227-248.

Gaut, Berys (2006). Art and Cognition. In Matthew Kieran (ed.), Contemporary Debates in Aesthetics and the Philosophy of Art. Oxford: Blackwell, 115-26.

Gerrig, Richard J. \& Deborah A. Prentice (1991). The Representation of Fictional Information. Psychological Science 2: 336-40.

Gilbert, Daniel T. ; Tafarodi, Romin W. \& Malone, Patrick S. (1993). You Can't Not Believe Everything You Read. Journal of Personality and Social Psychology 65 (2):221-233.

Goldstein, Daniel G. \& Gerd Gigerenzer (2002). Models of Ecological Rationality: The Recognition Heuristic. Psychological Review 109: 75-90.

Green, Melanie C. \& Timothy C. Brock (2000). The Role of Transportation in the Persuasiveness of Public Narrative. Journal of Personality and Social Psychology 79: 701-21.

Haselton, M.G. (2007). Error Management Theory. In R.F. Baumeister \& K.D. Vohs (eds.), Encyclopedia of Social Psychology, Vol. 1, Sage Press: 311-12.

Haselton, M.G. \& D.M. Buss (2000). Error Management Theory: A new perspective on biases in cross-sex mindreading. Journal of Personality and Social Psychology 78: 81-91.

Hazlett, Allan (2013). A Luxury of the Understanding: On the Value of True Belief. OUP Oxford.

Ichino, Anna \& Gregory Currie (XXXX). Beliefs from Fiction.

Konrad, Eva-Maria (XXXX). Signposts of factuality: On genuine assertions in fictional literature.

Kaufman, Geoff F. \& Lisa K. Libby (2012). Changing beliefs and behavior through experience-taking. Journal of Personality and Social Psychology 103: 1-19.

Lamarque, Peter (XXXX). Belief, thought, and literature.

Lewis, David (1970). An argument for the identity theory. Journal of Philosophy 63 (2):17-25.

Marsh, Elizabeth J. \& Lisa Fazio (2006). Learning Errors from Fiction: Difficulties in Reducing Reliance on Fictional Stories. Memory \& Cognition 34: 1140-9.

Marsh, Elizabeth J., Michelle L. Meade, Henry L. Roedinger III (2003). Learning Facts from Fiction. Journal of Memory and Language 49: 519-36.

McHugh, Conor \& Whiting, Daniel (2014). The Normativity of Belief. Analysis 74 (4):698-713.

McKay, Ryan T. \& Dennett, Daniel C. (2009). The evolution of misbelief. Behavioral and Brain Sciences 32 (6): 493-561

Millikan, Ruth G. (1984). Language, Thought and Other Biological Categories. MIT Press.

Neander, Karen (1995). Misrepresenting and Malfunctioning. Philosophical Studies 79: 109-41.

Papineau, David (1993). Philosophical Naturalism. Oxford: Blackwell.

Prentice, Deborah A. \& Richard J. Gerrig (1999). Exploring the Boundary Between Fiction and Reality. In Shelly Chailen \& Yaacov Trope (eds.), Dual Process Theories in Social Psychology. New York: Guilford Press, 529-46.

Prentice, Deborah A.; Richard J. Gerrig; Daniel Bailis (1997). What Readers Bring to the Processing of Fictional Texts. Psychonomic Bulletin \& Review 4: 416-20.

Putnam, Hilary (1967). Psychological predicates. In W. H. Capitan \& D. D. Merrill (eds.), Art, Mind, and Religion. University of Pittsburgh Press. 37--48.

Reisner, Andrew \& Steglich-Petersen, Asbjørn (eds.) (2011). Reasons for Belief. Cambridge University Press. 
Schroeder, Mark (2008). Being For. Evaluating the Semantic Program of Expressivism. Oxford University Press.

Shah, Nishi (2006). A New Argument for Evidentialism. Philosophical Quarterly 56: 481-98.

- (2003). How truth governs belief. Philosophical Review 112 (4):447-482.

Shah, Nishi \& Velleman, J. David (2005). Doxastic Deliberation. Philosophical Review 114 (4):497 - 534.

Sperber, Dan (1995). Anthropology and Psychology: Towards an Epidemiology of Representation. Man 20: 73-89.

Sperber, Dan; Clément, Fabrice; Heintz, Christophe; Mascaro, Olivier; Mercier, Hugo; Origgi, Gloria \& Wilson, Deirdre (2010). Epistemic Vigilance. Mind and Language 25 (4):359-393.

Strange, Jeffrey J. (2002). How fictional tales wag real-world beliefs. In M.C. Green, J.J. trange and T.C. Brock (eds.), Narrative Impact: Social and Cognitive Foundations. Marwah, NJ: Erlbaum. 263-86.

Steglich-Petersen, Asbjørn (2013a). Transparency, Doxastic Norms, and the Aim of Belief. Teorema 32.

- (2013b). Truth as the aim of epistemic justification. In Timothy Chan (ed.), The Aim of Belief. Oxford University Press.

- (2013c). The No Guidance Argument. Theoria 79 (1):279-283.

- (2011a). Against Essential Mental Normativity Again. Dialogue 50 (02):333-346.

- (2011b). How to be a teleologist about epistemic reasons. In Asbjorn Steglich-Petersen \& Andrew Reisner (eds.), Reasons for Belief. Cambridge University Press. 13--33.

- (2010). The Truth Norm and Guidance: a Reply to Gluer and Wikforss. Mind 119 (475):749-755.

- (2009). Weighing the aim of belief. Philosophical Studies 145 (3):395 - 405.

- (2008a). Against essential normativity of the mental. Philosophical Studies 140 (2):263 283.

- (2008b). Does doxastic transparency support evidentialism? Dialectica 62 (4):541-547.

- (2006a). No Norm needed: On the aim of belief. Philosophical Quarterly 56 (225):499_ 516.

- (2006b). Voluntarism and Transparent Deliberation. South African Journal of Philosophy 25 (2):171-176.

Stich, Stephen (1990). The Fragmentation of Reason: Preface to a Pragmatic Theory of Cognitive Evaluation. MIT Press.

Stokes, Dustin (2006). Art and Modal Knowledge. In Matthew Kieran \& Dominic M. Lopes (eds.), Knowing Art. Dordrecht: Springer, 67-81.

Sugiyama, Michelle S. (2001). Food, foragers, and folklore: the role of narrative in human subsistence. Evolution and Human Behaviour 22: 221-240.

Sullivan-Bissett, Ema \& Lisa Bortolotti (XXXX). Fictional persuasion, transparency, and the aim of belief.

Sutton-Smith, B. (1986). Children's fiction making. In T.R. Sarbin (ed.), Narrative Psychology: The Storied Nature of Human Conduct. New York: Praeger. 67-90.

Tverski, Amos \& Daniel Kahneman (1973). Availability: A Heuristic for Judging Frequency and Probability. Cognitive Psychology 5: 207-32.

Vaidya, Anand (2007). The Epistemology of Modality. The Stanford Encyclopedia of Philosophy.

Velleman, David (2000). On the aim of belief. In The Possibility of Practical Reason. Oxford University Press. 244--81.

Wedgwood, Ralph (2007). Normativism defended. In Brian P. McLaughlin \& Jonathan D. Cohen (eds.), Contemporary Debates in Philosophy of Mind. Blackwell. 85-- 
102.

Wheeler, Christian; Melanie C. Green; Timothy C. Brock (1999). 'Fictional Narratives Change Beliefs: Replications of Prentice, Gerrig, and Bailis (1997) with Mixed Corroboration. Psychonomic Bulletin and Review 6: 136-41.

Whiting, Daniel (2010). Should I Believe the Truth? Dialectica 64 (2):213-224.

Williams, C.G. (1966). Adaptation and Natural Selection: A Critique of Some Current Literary Thoughts. Princeton University Press.

Williams, Bernard (1973). Deciding to Believe. In Problems of the Self. Cambridge: Cambridge University Press, 136-52.

Young, James (XXXX). Literary fiction and true beliefs.

Zangwill, Nick (1998). Direction of fit and normative functionalism. Philosophical Studies 91 (2):173-203. 